hand, that of potatoes and cereal products, including bread and flour, is decreasing yearly. In 1960 the decrease for potatoes was temporarily halted as they were cheap and plentiful, but over the five-year period decline in purchases can be seen. Purchases of cereal foods are now 14 per cent less than the pre-War level; only $45.5 \mathrm{oz}$. of bread per person per week was purchased in 1960 compared with 47.3 in 1959 and $51.1 \mathrm{oz}$. in 1956. A change of taste is shown in the rapidly growing demand for wrapped bread. Less flour is being bought and more cakes and biscuits.

With respect to 'convenience foods', most of the money is spent on cakes and biscuits, cannod or cooked meat and fish, but 21 per cent is spent on fruit and vegetables and the greatest expansion of demand has been for frozen legumes, mainly peas. In 1956, $0 \cdot 2 \mathrm{oz}$. of frozen legumes per person per week were purchased, rising to $0.63 \mathrm{oz}$. in 1960 . The popularity of frozen foods is indicated by the fact that they are grouped separately in the 1960 report and not included in other groups. Although an average of $5 s$. $6 d$. per head per week was spent on 'convenience foods', this was by no means uniform. The section on diet and social classes shows that $6 s .3 d$. a week was spent on them by the highest earning income group, but only $4 s$. 10d. by the lowest, while old-age pensioners spent $3 s$. 11d. The section on family composition shows that young childless couples spent $8 s$. $1 d$. per head per week on 'convenience foods' compared with $3 s$. 11d. spent by families with four or more children. Geographical comparisons indicate that the highest proportion of the total expenditure on foods devoted to 'convenience foods' was in the north of England and Scotland and the lowest in London and the rural areas.

When the housewife goes out to work she has less time but more money to spend on food, and, as a result, she devotes more money to prepared foods. This trend is likely to increase as mass production and competition reduce the price of these foods and make available a greater variety. Enthusiastic lovers of home-cooking evoke little response from harassed housewives who do not want to be 'slogging away over a hot stove' in a machine-minded age, and can afford to buy foods which reduce the slogging. Although the average value for food consumed (including 'free supplies' from gardens, etc.) was $30 s$. 6d. per person per week in 1960, the highest income group was obtaining food worth $40 s$. $3 d$. and the lowest 27s. 4d. An increase in the basic pensionrate in 1958 was reflected in a welcome increase of expenditure on food by old-age pensioners from $24 s$. $9 d$. in 1956 to $27 s$. $10 d$. in 1960 (the total value being 28s. 6d. including 'free foods'); part of this is, however, accounted for by the rise in food prices since 1956. The expenditure of families of different sizes shows a wide range. Families of two adults under 55 spent $40 s$. $3 d$. per head per week (41s. $2 d$. with 'free foods'), while families with four or more children spent only $19 s .9 d$. (20s. $3 d$. with 'free foods').

The survey showed that the population as a whole had a diet adequate in all respects. The higher expenditure of wealthier families means more expensive foods and a greater variety, but little nutritional advantage except for more vitamin $\mathrm{C}$ resulting from a higher consumption of fruit and vegetables. The blot in this happy picture remains the consumption of families with several children. Households with three children obtained only 92 per cent and 94 per cent of estimated requirements for protein and calcium respectively. Those with four or more children obtained 99 per cent of the energy value neoded, but only 85 per cent of the total protein and 85 per cent of the calcium. Growing children should not go short of protein and calcium. The over-all picture of well-being and rising standards of living, based on encouraging average figures, may conceal the position of some less-fortunate minorities.

Joyce Doughty

\title{
FOOD ADDITIVES AND MEAT HYGIENE
}

$\mathrm{T}$ WO booklets containing reports of Joint Food and Agriculture Organization/World Health Organization Expert Committees have recently been published. Problems in connexion with the satisfactory control of food additives are discussed in No. 31 of the Food and Agriculturo Organization Nutrition Meetings Report Series, which is entitled Evaluation of the Toxicity of a Number of Antimicrobials and Antioxidants*. Some 86 pages of the booklot contain a series of monographs relating to a selected number of preservatives and antioxidants. The substances chosen for evaluation by the Joint Committee were those which are widely used in many countries and because they play an important part in reducing food wastage by improving storage efficiency and distribution. Specifications for identity and purity of additives were discussed in previous reports of the Committee. The monographs of this, the sixth report of the Joint Committee on Food Additives, therefore, concentrate largely on the

* Food and Agriculture Organization of the United Nations. FAO Nutrition Meetings Report Series. No. 31. Evaluation of the Toxicity of a Number of Antimicrobials and Antioxidants. Sixth Report of the Joint FAO/WHO Expert Committee on Food Additives. Pp. 104 London: H.M. Stationery Office, 1962.) 6s. $8 d$.; 1.25 dollars. properties that are of the greatest interest to the toxicologist. The biological data are presented under the following headings: acute toxicity, short-term studies, long-term studies and biochemical aspects.

Each monograph records the comments of the Committee on such data, but the report mentions that in most cases they would have liked more evidence from which to draw. For the evaluation of the individual preservatives and antioxidants, the Committee have (wherever possible) estimated: $(a)$ the dosage-level causing no significant toxicological effect (mainly from long-term studies in rats); (b) the acceptable daily intake zones for man (unconditional and conditional). The latter figures are also usefully given in tabular form on page 12. The Committee recommends that the Food and Agriculture Organization and the World Health Organization should use all means available to promote further research and that further committees should be convenod to evaluate the toxic hazards involved in the use of other groups of additives, such as emulsifiers, stabilizers, other preservatives, such as antibioties, and food colours. It is interesting to note, however, that this report states that ". . . the needs for food additives and their possible uses and applications vary so widely 
from country to country that a single pattern of legislation is not feasible on a world-wide basis".

A somewhat different aspect of food quality is discussed in No. 24l of the World Health Organization Technical Report Series $\dagger$. This publication stresses that the world scarcity of protein makes it necessary to conserve and utilize meat supplies to the fullest possible extent. This requires the application of a meat hygiene system which includes supervision of the meat production chain from the farm, through transport to a well-run abattoir, to distribution to the

$\dagger$ World Health Organization. WHO Technical Report Series, No. 241, and/or FAO Agricultural Studies, No, 58: Joint FAO/WHO Expert Committee on Meat Hygiene-Second Report. Pp. 88. (Geneva World Health Organization; London: H.M. Stationery Office, 1962. 3 Swiss francs; 5 s.; 1 dollar. consumer. This booklet covers each of these stages separately, for example, diseases, slaughter, inspection, refrigeration, transport, marketing, manufacture, sanitation of retail shops and restaurant kitchens, hygiene of handlers, education, newer developments and laboratory methods. A separate section on poultry hygiene is also included. The Committee recommends that the Food and Agriculture Organization and the World Health Organization should encourage further investigation into various problems related to meat hygiene, including those associated with chomical residues, meat-borne diseases, rapid methods for diagnosing organisms and the presence of radionuclides.

D. Pearson

\section{FISHERIES OF NIGERIA}

TN an excellent report*, Mr. A. R. Longhurst sums 1 up the fisheries situation in Nigeria and its future requirements. He estimates that at present only some 58,000 out of Nigeria's fish supplies of 203,000 tons are produced locally, the rest being imported, and that, even so, the supply of fish per head of the population is only $11.36 \mathrm{lb}$. per annum. He doubts whether the indigenous sea fisheries, even if improved by some mechanization and other possible developments, will go far to fill the gap; and the small fleet of foreign-owned inshore trawlers has only limited prospects of expansion. Mr. Longhurst thinks that the best prospects lie in the exploitation of distantwater fisheries, both pelagic (especially the tunas) and demersal. But for this much capital and expertise will be needed, and there is especially the need of a deep-water fishing harbour with all the ancillary facilities without which foreign fishing enterprises are unlikely to be able to work from Nigeria.

There is an interesting account of the freshwater fisheries, indicating scope for expansion in the potentially rich fisheries of Lake Chad. Mr. Longhurst summarizes the research and development work that has already been done in Nigeria and West Africa in general, but the picture was not one of sustained effort. There is a very useful bibliography.

* Report on the Fisheries of Nigeria 1961. By A. R. Longhurst. Pp. 53. (Lagos: Federal Fisheries Service, Ministry of Economic Development, 1962.)
In his summary of the hydrographic situation, Mr. Longhurst shows that Nigeria lies in the area between the relatively rich cold water of the Benguela and Canary Currents, and is subject to the warm nutrient-poor Guinea Current. But the big rivers, and especially the Niger, bring down in their annual floods important amounts of organic matter. The great influence of the thermocline in the distribution of the fish is restated.

Based on this summary, Mr. Longhurst describes the research work begun by the Federal Fisheries Service, which has its headquarters at Lagos but can undertake research anywhere in Nigeria, at the request of the regional authorities. There is an establishment of a director and five research officers, a small band for so large a territory with such diverse problems. A 70 -ft. research vessel has been recently acquired, and surveys are being made of the fish and crustacean resources, as well as hydrographic sections and plankton work. Research on fish includes a study of the life-histories of the most important species; in conjunction with studies of mesh-selection and of the fishing effort, it is planned to get the information needed for a rational management of the inshore trawl fisheries.

Those who know how difficult it is to start and carry on such a programme will wish the Federal Fisheries Department well in their important work.

C. F. HICKLING

\section{AMATEUR RADIO ASTRONOMY}

$\mathrm{R}$ ADIO astronomy has attracted to itself a band of amateurs no less zealous than those who are devoted to optical astronomy. The techniques required for the simplest observations are more complex than those required to build a small optical telescope and most of the work done so far has necessarily been by groups of amateurs who have combined resources and experience to build aerials and receivers and have worked together on the assessment of observations. The Radio Electronics Section of the British Astronomical Association has co-ordinated this work and has recently published a mernoir on "Radio Astronomy and Radio Telescopes" (40, No. 1; 1962 February) edited by Dr. J. Heywood.

This memoir sets out to provide a useful introduction for a beginner to the techniques of radio astronomy. A helpful description is given of theoretical and practical fundamentals of the aerial and receiver design of the basic installation necessary for amateur observations.
An encouraging aspect of amateur interest in radio astronomy in Great Britain is its youth. Six of the contributors to the memoir were under twenty-one when they wrote their articles. Two of these were sixth-form schoolboys who wrote their contribution on the physical principles of radio wave propagation and reception. A recent publication in the Journal of the British Astronomical Association $(72,19 ; 1962)$ describes work by another sixth-form student, J. K. Sabbagh, on "An Analysis of Extraterrestrial Records at $27 \mathrm{Mc} / \mathrm{s}$ ".

Many types of observation are possible with simple receivers. These include observations of the strong radio sources with interferometers and the effects of the ionosphere on the incoming signals; the Sun and Jupiter can be studied for their variability. The professional radio astronomer heartily encourages this field of amateur activity.

R. D. Davies 